\title{
Strategic Framework and Maturity Index for Measuring Knowledge Management Practices in Government Organizations
}

\author{
Shilpa Vijaivargia \\ Head (IT), Consultancy Development Centre, Department of \\ Scientific and Industrial Research, Ministry of Science and \\ Technology, New Delhi, India
}

\author{
Dr. Hemant Kumar Garg \\ Lecturer (Selection Grade), \\ Govt. Women Polytechnic College, \\ Jaipur, Rajasthan, India
}

\begin{abstract}
Knowledge is considered as an intellectual asset of any Organization through which performance of the Organization could be enhanced exponentially. Harnessing of the Organization's Tacit and Explicit knowledge and its Management is a crucial task as Knowledge Management Practices adopted by Government Organizations are not standardized yet. They are depending on the structure and processes adopted by the organizations at their own level. This paper presents a Strategic Framework of Knowledge Management and defines Maturity Index at three levels for measuring Knowledge Management Practices adopted by an Organization. This paper defines Value of the Knowledge at all the three defined Maturity levels which is based on number of times the knowledge content is viewed, benefits gained against viewing such contents in terms of tangible asset and SocioEconomic Impact. Knowledge Management Practices adopted by Bharat Electronics Limited (BEL) studied and measured at the Maturity Level is defined in this paper.
\end{abstract}

Keywords-Knowledge; Explicit knowledge; Tacit knowledge; knowledge management; knowledge architecture; knowledge process framework; knowledge audit; maturity index; knowledge audit

\section{INTRODUCTION}

Knowledge needs to be managed timely and cost effectively in order to streamline processes. Storage of knowledge in structured manner generates a repository of it which would help in accessing the knowledge contents as per the requirements. Knowledge Management helps organization to perform its tasks with more efficacies in less time. If it is developed through IT platform, provides the overall strategy to manage the e-contents by providing Knowledge Management tools and techniques, monitoring updates on knowledge contents and define mechanism to access the contents as per the defined roles. Such a Knowledge Management System supports the concept of e-governance and becomes part of it.

The benefits of Knowledge Management in government are bringing conduciveness to enhance government's competence, raising government's service quality and promoting development of e-repositories. It also helps in bringing transparency through execution of processes as per the defined rules and mechanism results in value oriented government. In today's digital era, success of e-governance depends and directly proportionate to knowledge management practices adopted by the Organization [1].

IT based Knowledge Management Practices had initiated in Indian Government Organizations three decades ago, but many of the Government organizations are still facing challenges to transform its knowledge available in manual processes into electronic format due to inappropriate categorization of data, non-structured storage, non-defining of schemas, metadata and ontology for government processes.

Knowledge, its Architecture and connecting elements in brief are described in Section II, Maturity levels for measuring Knowledge Management Practices adopted by the Organizations are given in Section III with a Framework of Knowledge Management Process Workflow. Knowledge Management Systems studied for BEL along with measuring its Knowledge Practices with the defined Maturity levels are given in Section IV. Limitations of the study are given in Section V. Conclusion and Future Work is provided in Section VI.

\section{KNOWLEDGE, ITS MANAGEMENT AND ARCHITECTURE}

Knowledge has been defined by various researchers. One of the definition is "Knowledge is a fluid mix of experience, values, contextual information and expert insight that provides a framework for evaluating and incorporating new experiences and information. It is often embedded not only in documents or repositories but also in organizational routines, processes, practices, and norms [2]". Similarly, Knowledge Management (KM) could be defined as "The creation and subsequent management of an environment, which encourages knowledge to be created, shared, learnt, enhanced, organized and utilized for the benefit of the organization and its customers" [3].

The architecture of Knowledge Management can be broadly categorized in the following four layers (Fig. 1): 


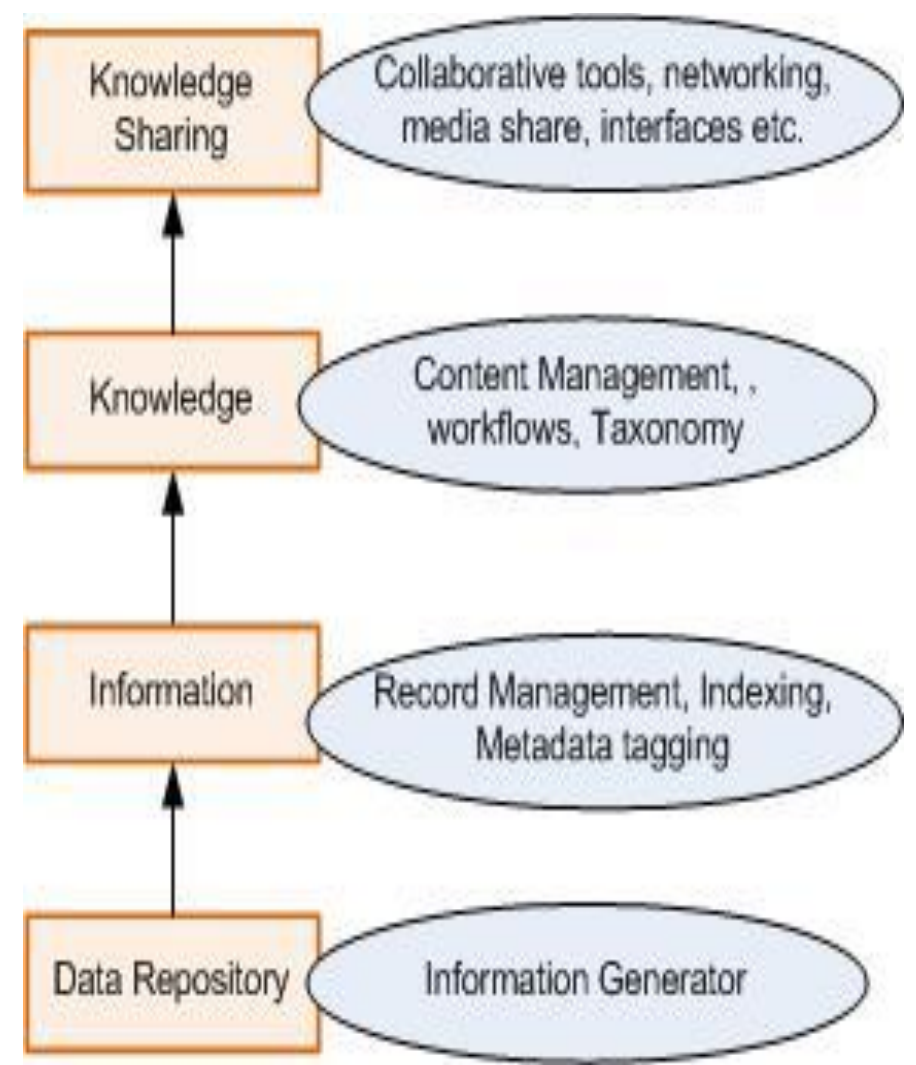

Fig. 1. KM architecture.

Generation of knowledge is based on data capturing techniques from data repository. The data is transformed into information through segregation of it on usability basis. The information gets classified through hashing, indexing and tagging which further converted into knowledge supporting taxonomies, workflows, multilevel navigation and federated search mechanism on the Content Management System (CMS) which can be shared through presentation interfaces and networking tools as per the defined rules.

\section{MATURITY INDEX FOR ANALYSING KM IN AN ORGANIZATION}

Though, various Knowledge Management Systems are available nowadays in standard and customized form such as Microsoft SharePoint, IBM Lotus Notes, SAP NetWeaver, Sales force, eXo platform, etc., yet there is no standard practice on which maturity level of KM Systems implemented by the organization can be measured [6]. KM practices at three levels are defined here. The characteristics of each level as defined are as follows:

\section{A. Maturity level I-Beginner's Level}

A KM activity initiated and carries out in the organization on voluntary basis. There is no well-defined Institutional framework for KM. Work related to KM activities carried by existing official giving him additional charge for it. Ontology, roles and privileges are not defined or strictly follow in binding with knowledge resources. IT enabled technology does not well merge with the rules and procedures for KM and are not linked through Strategic goals of the organization.

Value of Knowledge $(\mathrm{Kb})=$ (Number of times the uploaded Knowledge resources had accessed in a defined interval in a particular category/ Total Knowledge resources uploaded in that category) $* 100$

Wherein

Defined interval $=$ the time defined by the organization in which number of tasks were performed

\section{B. Maturity level II- Intermediate Level}

A team is placed to work, monitor and review Knowledge Management activities. Various initiatives are taken to promote KM in the organization such as direct talks, seminars, workshops, media promotional tools, etc. Technology leveraged to support Knowledge Management along with IT enabled features for navigation, search, role base authority, etc. Organization realises link of Strategic goals to available knowledge. The Value of Knowledge can be assessed as:

Value of Knowledge $(\mathrm{Ki})=[[$ (Number of tasks performed in reduced time in defined interval)/(Total number of tasks performed in defined interval)] $* 100+\mathrm{Kb}] / 2$

\section{Wherein}

Reduced time $=$ the time which is less than $(<)$ average time taken for performing a task in the defined interval

\section{Maturity level III-Mature Level}

A dedicated team takes care of KM related activities. Institutional mechanism supports KM activities which are linked to Organization's Objectives and strategic goals. Tools and technologies are enough mature to access, search and modify knowledge resources as per the assigned role privileges and could be upgraded as per the requirements. Uploading of knowledge resources aligned with process workflows related to role privileges and linked to Annual Performance Appraisal Report (APAR) of the employees. Knowledge Audit gets performed and total value of the knowledge can be assessed through Internal and External both factors.

Value of Knowledge $(\mathrm{Km})=[($ Value measured in tangible form through Knowledge Audit on scale of 100) + (Conversion of Socio-Economic Impact of Knowledge through Knowledge Audit on scale of 100) $+\mathrm{Ki}] / 3$

\section{Wherein}

Knowledge Audit (Tangible form of Knowledge) = (Increase in performance of employee evident through measurements mentioned in their APAR)

Knowledge Audit (Intangible form of Knowledge which is Socio-Economic Impact) $=$ Benefits in terms of socioeconomic status by using the knowledge (based on inputs from knowledge users for a respective knowledge)

A Knowledge Management Process Framework is given below for all the three levels as aforesaid mentioned (Fig. 2). 


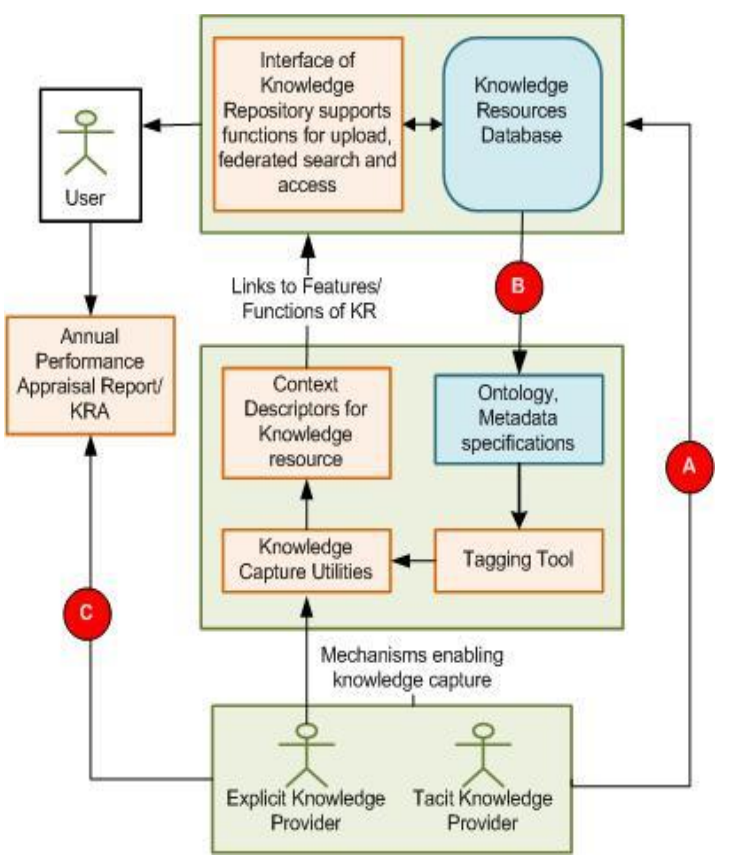

Fig. 2. Strategic framework of KM.

IV. KNOWLEDGE MANAGEMENT AT BHARAT ELECTRONICS LIMITED (BEL)

\section{A. Background}

Bharat Electronics Limited (BEL) was established by Government of India in 1954 under Ministry of Defence to cater Electronics need of Defence. It works in professional Electronics for Defence and other organizations. The work associated with BEL requires storage of voluminous and highly diverse documents which could be in the form of standards, manuals, technical specifications, research papers, articles, power point presentations, conference proceedings, ebooks, workflow of procedures, contracts and agreements. Knowledge Management of such documents helps in reducing learning time period for a definite process workflow which results in increase of productivity of manpower [4].

\section{B. Knowledge Management Workflow Adopted by BEL}

A Knowledge Officer is designated to perform Knowledge Management related activities in BEL, which is supported by cross functional groups work in technology and innovation promotion. BEL encourages their employees to use KM Systems through circulation of Guidelines regarding access and use of KM Practices and workshops conducted time to time. KM system in BEL accepts knowledge pieces in the form of document, image or in other form. Knowledge contributor sends knowledge content(s) to Knowledge Officer along with context descriptor and other requisite details. Subsequent to the review and approval of Competent Authority on the sent content(s), it is accessible to its stakeholders based on their roles and authorized privilege for sharing and viewing [4].

\section{Tools and Technology used for KM}

BEL uses SAP based technology for its Knowledge Management Systems. The information may be captured from file server or intranet as per its defined rules. The functional unit can integrate multiple repositories to share its contents due to which contents from various units of BEL could be shared and accesses through a centralized platform [5].

The System supports multilevel navigation and advanced search mechanism to access the information based on their privileged roles. Knowledge contents are classified through taxonomies as defined. This feature also supports online messaging and sharing of information on real time and concept of Virtual rooms [5].

\section{Measurement of KM Systems at BEL as Per the Defined Maturity Index}

Knowledge Management Systems at BEL supports in speeding of their deliverables through usage of available manuals, standards, workflows etc. Hence, standardization and dissemination of processes helps in achieving deliverables in time. The manpower exchange knowledge pieces through interactive platform as per the requirements and authorized privilege which helps in reducing the learning curve. However, some of the manpower is habitual to work on Windows platform did not find SAP based KM System much user friendly. Therefore, awareness about KM systems required to be further strengthened. KM systems at BEL found at Maturity level II- Intermediate level as defined in this paper with an interval of 10 days.

\section{LIMITATIONS OF THE STUDY}

Value of Knowledge can be measured at Maturity level IBeginner's level and Maturity level II- Intermediate level on definite parameters as it is based on data analytics provided by the system supporting digital Knowledge Repository. However, Value of Knowledge at Maturity level III- Mature level cannot be analysed without sharing compiled information on the parameter: Number of Knowledge articles read through digital Knowledge Repository which has to link with Performance improved of the employee. Such information to be extracted from employee's APAR for the category of employees through which Value of Knowledge to be measured and a Review Report which has assessed SocioEconomic Impact of the Knowledge stakeholders in a particular category. Similarly, results extracted from Knowledge Audit which is conducted by third party on individual basis need to be shared for measuring Value of Knowledge at Maturity level III- Mature level.

\section{CONCLUSION AND FUTURE WORK}

This paper defines Knowledge, its main elements, tool and technologies used for Knowledge Management in brief. Knowledge Management Architecture, a Framework containing process workflow of Knowledge Management Systems and Knowledge Management Maturity Index at three levels presented in the paper based on study and understanding of structure and processes followed by Government Organizations. Equations from extraction of Value of Knowledge could be extracted for each Maturity level. Learnings gained from study of BEL also helped in defining the framework and Maturity Index of Knowledge Management Systems in Government Organization. 
Knowledge Management Practices adopted by BEL is mapped on the defined Maturity level.

Further, BEL or any other Government Organization may be mapped at Maturity Index and Value of Knowledge can be extracted from the relationships presented in this paper. Organizations' knowledge may be got audited and Value of knowledge may be extracted. Socio-Economic Impact and conversion of intangible benefits in tangible asset may be worked upon.

REFERENCES

[1] Florian Resatsch et.al, Measuring the performance of knowledge management initiatives, 2004
[2] James Sheffield, Pluralism in Knowledge Management: a Review University of Auckland, New Zealand, 1998(URL: file:///C:/Users/shilpa/Downloads/ejkm-volume7-issue3-article190.pdf)

[3] Angela Abell and Nigel Oxbrow, Competing with Knowledge, The information professional in the knowledge management age, 2006, Paperback 9781856045834

[4] CDC Study Report by Deloitte, Study and Analysis of Knowledge Management Systems in Indian Government and Public Sector Organization for generating a model framework for Knowledge Management System including compilation of success stories, 2015

[5] Knowledge Management for the Public Sector; Asian Productivity Organization, 2013,

[6] Dr.Alea M. Fairchild, Knowledge Management Metrics via a Balanced Scorecard Methodology, 2002 